\title{
Assessment and instruction of object permanence in children with blindness or multiple disabilities
}

\author{
Authors: Susan Bruce, Claudia Vargas
}

Persistent link: http://hdl.handle.net/2345/3251

This work is posted on eScholarship@BC, Boston College University Libraries.

Post-print version of an article published in Journal of Visual Impairment \& Blindness 106(11): 717-727.

These materials are made available for use in research, teaching and private study, pursuant to U.S. Copyright Law. The user must assume full responsibility for any use of the materials, including but not limited to, infringement of copyright and publication rights of reproduced materials. Any materials used for academic research or otherwise should be fully credited with the source. The publisher or original authors may retain copyright to the materials. 


\begin{abstract}
Assessment and Instruction of Object Permanence in Children with Blindness and Multiple Disabilities
\end{abstract}

\author{
Susan M. Bruce, Ph.D. \\ Associate Professor \\ Claudia Vargas, Ph.D. Candidate \\ Boston College \\ 120 Campion Hall \\ 140 Commonwealth Avenue \\ Chestnut Hill, MA 012467 \\ susan.bruce@bc.edu
}




\begin{abstract}
Introduction: Mastery of object permanence is essential to the development of representational thought and language. This article discusses the impact of visual impairment and blindness on the development of object permanence and provides suggestions for assessment and instruction.

Methods: The reviewed literature was identified by searching both ERIC and Psych Info using search term combinations such as object permanence and visual impairment, blind, or multiple disabilities. Books, assessment tools, and non-peer reviewed literature were also reviewed.
\end{abstract}

Results: While children with low vision may use vision as the basis to mastery object permanence, children who are blind will rely primarily on their tactile experiences of objects. Object permanence and orientation and mobility share a reciprocal relationship. Recommended instructional practices include consistent and repeated naming of the concealed object, concealment of motivating and varied objects, direct reinforcement, structured play spaces, and prompting to success.

Discussion: While the sequence of object permanence mastery is similar for sighted and blind children, the approach to mastery is different for children who are blind. Direct instruction that is grounded in careful assessment may accelerate mastery of object permanence, with unique strategies being applied to the instruction of children who are blind.

Implications for Practitioners: Practitioners may use the structured informal assessment and the identified items within commercially produced assessment tools to understand the child's current level of performance in the area of object permanence. Practitioners can 
also integrate the research based and promising practices, shared in this article, to improve instruction. 
Assessment and Instruction of Object Permanence in

Children with Blindness and Multiple Disabilities

\section{Introduction}

Object permanence, knowing that objects continue to exist when they cannot be seen (or touched in the case of children who are blind) is one of the most important early developmental milestones (Fazzi \& Klein, 2002; Morss, 1984). In the field of visual impairment, the term "object concept" is used synonymously with object permanence (Warren, 1994). Like means-end, deferred imitation, self-recognition, and symbolic play, object permanence is associated with the onset of representational thought and language (Bruce, \& Zayyad, 2009; Fazzi \& Klein, 2002; Wright, 2006). Many researchers believe that mastery of full object permanence is necessary to the development of language (Hammes \& Langdell, 1981; Moore, Borton \& Darby, 1978; Piaget, 1954). This article reviews literature on the development of object permanence in children who are sighted, (including those with low vision) or blind. This literature was identified through the ERIC and Psych Info data bases using combined search terms such as object permanence and visual impairment, blindness, and multiple disabilities. Books, assessment tools, and non-peer reviewed literature were also reviewed. Suggestions about appropriate assessment tools and a structured informal assessment are included to support teachers to identify present levels of performance. Research based and promising instructional strategies are described.

\section{Object Permanence in Children with Sight or Low Vision}

Visual tracking, visually directed reach, and grasp are precursor skills to demonstrating object permanence in children with sight (Robinson \& Robinson, 1978) including children with low vision. Early object permanence is demonstrated when 
children are able to retrieve objects that are completely concealed when they have observed the concealment. This is possible because causality and goal directed behaviors have been achieved (Piaget, 1952, 1954). Children at this level make the classic A-not-B error. This occurs when children are able to retrieve a hidden object at the first location of concealment (A) but fail to retrieve it at the second location (B) even though they have visually observed concealment (Piaget, 1952, 1954). Visual attentiveness to the current location of the object is critical to resolving the A-not-B error in children (Horobin \& Acredolo, 1986). Thus, children with low vision may especially struggle with the A-notB error phase because they are using their vision as the basis for mastering object permanence.

Once children acquire mean-end knowledge, they are able to retrieve objects hidden in several locations, although this is still bound to visually observing the concealment (Piaget, 1952, 1954). Finally, with the development of mental representation (being able to create mental images and hold them in mind) they are able to solve more advanced object permanence problems (Wright, 2006). Children are now able to reason about where the object might be when invisible displacement occurs.

Children with sight achieve object permanence gradually basing mastery of the more simplistic tasks on their visual perception and the more advanced tasks involving invisible displacement on later developed mental representation (Simpkins, 1979; Wright, 2006). Even a small amount of functional vision is helpful to the achievement of object permanence (Bigelow, 1990). However, poor understanding of spatial environments may contribute to delays in the achievement of object permanence by children with visual impairments (Warren, 1994). 


\section{Object Permanence in Children Who Are Blind}

The sequence of object permanence development is similar for children who are blind but their approach to mastery is very different (Rogers \& Puchalski, 1988). Project Prism (Ferrell, 1998) measured multiple developmental milestones in 202 children with visual impairment and then compared their findings to developmental ages of sighted children. They found that children with visual impairment were delayed in searching for a dropped object. One explanation for this may be that children who are blind often persist in the belief that objects magically disappear and reappear because that is their experience of objects (Bruce \& Zayyad, 2009). The closely related achievements of reaching toward sound and reaching to search for objects (that occur prior to object permanence) emerge at about 8 months in children who are blind and initially occur just after objects have been explored tactilely (Fraiberg, 1977). In time children learn to search but initially do so only in the last location in which they physically interacted with an object (Fraiberg, 1977). Around 11 months, children who are blind are able to reach for objects that they have not heard (Fraiberg, 1977, Ross \& Tobin, 1997).

The development of object permanence in children who are blind is based more on their tactile experiences of objects than on their auditory experiences. Auditory input alone is insufficient to support the development of object permanence in children who are blind (Fraiberg, 1977; Gerhardt, 1982). This is because it is difficult to distinguish one sound from another and to then develop a 1:1 correspondence between a specific sound and a specific object (Harrell, 1983) which would then motivate reaching and searching (Fraiberg, 1977; Schwartz, 1984). Nielsen (1992) asserted that one of two conditions must exist for sound to be meaningful to object permanence development: (1) the sound 
in distant space is continuous (until the child reaches the source of the sound) or (2) the child has already achieved the skill of recognizing the sound (sound-object association) and can determine the source of its direction if the sound ceases. Thus, sound alone is only useful after the early stages of locating objects (based on experiencing concealment) are mastered. Sound must be paired with the tactile exploration of objects so that children who are blind are supported to build object-sound associations (Schwartz, 1984). Then, sound can serve as an invitation to move into distant space to locate desired objects.

The sense of touch is central to learning about objects and to achieving object permanence for children who are blind. The construct of "object constancy" is important to understanding the achievement of object permanence in children who use tactile input to master object permanence (Anthony, Bleier, Fazzi, Kish, \& Pogrund, 2002; Hatton, Anthony, Lowry, \& Brown, 2004). Through repeated and thorough tactile exploration of objects, children come to recognize that the characteristics of explored objects remain constant. This supports them to recognize the object even when they touch just part of it, a skill that is essential to demonstrating object permanence knowledge (especially in partial concealment tasks). Tactile experiences with objects support children to learn about the properties of objects including how they move in and out of the child's near space. Children are more likely to reach for objects that they have both touched and heard rather than those they have only heard. Ross and Tobin (1997) caution that a lack of search behavior does not necessarily mean that children who are blind do not understand object permanence. They may not search because they do not recognize the potential impact of their actions on objects. Thus, tactile experiences with objects are critical to knowing the effects one can have on them and also serve to motivate search behaviors. 
While their sighted and low vision peers learn about the more basic object permanence tasks through visual perception, children who are blind must always use their memory and their ability to conceive (hold an idea in mind) rather than perceive to understand the permanence of objects (Simpkins, 1979). This is why children who are blind are delayed in achieving the early tasks of object permanence, yet overcome the Anot-B error more quickly than children who are sighted (Rogers \& Puchalski, 1988). The delay at the A-not B error stage for children who are sighted is thought to be due to their memory deficits. In contrast, children who are blind rely on conceptual understandings and memory rather than perceptions at the earlier stages of object permanence (Rogers \& Puchalski, 1988). Thus, they excel at the higher-level object permanence tasks that are also grounded in conceptual understandings and memory.

\section{Object Permanence in Children with Multiple Disabilities and Visual Impairment}

Children with multiple disabilities and visual impairment often have intellectual and physical disabilities. Children with intellectual disability alone achieve object permanence in a similar developmental sequence and at the same mental age as children without disabilities (Hupp, Able, Conroy-Gunter, 1984; Silverstein, Pearson, Keller \& McLain, 1982). Motor disabilities may influence the development of object permanence or the ability to demonstrate object permanence knowledge (Bruce \& Zayyad, 2009). Children with motor limitations may require alternative means to demonstrate object permanence knowledge, such as searching with their eyes (if they have sufficient functional vision) or communicating what they know about object permanence as opposed to demonstrating their knowledge through physical search (Eagle, 1985). There is almost no research on the achievement of object permanence in children with multiple 
disabilities, making it difficult to understand the effects of combined vision, motor, and intellectual disabilities on mastery of object permanence. McDonnell (1988) asserts that the achievement of object permanence by children with multiple disabilities is dependent on motor skills and mental age.

\section{Orientation and Mobility and Object Permanence}

Object permanence and orientation and mobility share a reciprocal relationship. Body concepts and body-to-object relationships are foundational to orientation and mobility and to object permanence. "With young children, orientation can be directly tied to the cognitive mastery of the concepts body image, spatial constructs, causality, means and ends, and object permanence.” (Anthony, Bleier, Fazzi, Kish, \& Pogrund, 2002, p. 328). Delays in object permanence mastery have been associated with delays in reaching and locomotion (Hatton, Bailey, Burchinal, \& Ferrell, 1997). Some precursor skills to object permanence, such as reaching independently toward objects, may not occur until the child who is blind has gained concepts about people and objects within the environment (Anthony, Lowry, Brown, and Hatton, 2004). The passivity of some infants who are blind may limit their opportunities to explore and the conceptual understandings that are grounded in that exploration (Nielsen, 1992). Sound alone is not a substitute for the motivation to move provided by vision (Adelson \& Fraiberg, 1974). Interestingly, when reach to sound is demonstrated, independent mobility soon follows.

With early independent mobility (such as crawling) visual attentiveness grows. In a study of fifty-six sighted infants, Horobin and Acredolo (1986) found length of time in independent mobility to be predictive of visual attentiveness and that visual attentiveness supported the achievement of later phases of object permanence, such as resolution of the 
A-not-B error. Egocentric spatial understandings that may contribute to the A-not-B error are challenged as children move and realize that as they move, the position of objects shift in relationship to their bodies (what was on the right may now be on the left as they move about) (Acredolo, 1990; Horobin \& Acredolo, 1986). As mobility develops, children use object permanence knowledge to engage in spatial updating (monitoring the position of their bodies in movement to permanent objects in space) (Bozeman and McCulley, 2010). Mobile children learn that watching an object (and its movement) is a good strategy for knowing its location (Hobobin \& Acredolo, 1986). Thus, early independent mobility seems to improve visual attentiveness, which is related to the achievement of object permanence in sighted children, including those with low vision.

\section{Assessing Object Permanence}

Good quality instruction is grounded in thorough assessment. When assessing children with visual impairment, including those with multiple disabilities, one must consider how task requirements, learner characteristics, and environmental factors might influence performance (Forney \& Heller, 2004).

After reviewing and coding ten commercial assessment tools developed for use with children who are blind and children with multiple disabilities, our research team selected several assessment tools for their breadth of coverage of the concept of object permanence and/or their common use with this population. Table 1 depicts the identified assessment tools, the section, page number, and item number for each item that measures object permanence and a few items that measure very closely related precursor skills (such as visually directed reach). The information in this table is intended to support teachers who need to identify appropriate assessment tools for assessing present levels of 
performance to cite on the Individualized Education Plan (IEP) and as the basis for lesson development. The Oregon Project for Visually Impaired and Blind Preschool Children, Second Edition (Anderson, Boigon, \& Davis, \& deWaard, 2007), The Callier-Azusa Scale (Stillman, 1978) and The INSITE Developmental Checklist: A Comprehensive Checklist for Multihandicapped Sensory Impaired Infants and Young Children (Morgan, 1999) were developed for use with children who have visual impairment with the latter two assessments were also designed for use with children who are deafblind. The INSITE Developmental Checklist for Multihandicapped Sensory Impaired Infants and Young Children (Morgan, 1999) includes accommodations for visual impairment and motor disability. Both the Hawaii Early Learning Profile (HELP), Birth to 3, Second Edition (Parks, 2004) and the Carolina Curriculum for Infants and Toddlers with Special Needs (Johnson-Martin, N. M., Attermeir, S. M. \& Hacker, B. J, 2004) include instructional materials on object permanence but these assessments are most appropriate for use with children who have sufficient functional vision to observe the concealment and disappearance of objects.

In addition to the above assessments, Assessing Interactions with Objects (Chen, Friedman, \& Calvellos, 1989) provides helpful items on precursor skills and also a few object permanence items. This assessment tool is part of the materials disseminated by the Parents and Visually Impaired Infants (PAVII) project. Tactile adaptations are included for the items. Precursor skills can be found in the sections on manipulative exploration and functional hand use. The object permanence skills are located in the section on problem solving (p. 10). Sample items include: "searches briefly for object at 
point of disappearance (visual or tactile)" and "finds object hidden under scarf " (Chen, Friedman, \& Calvellos, 1989, p. 10).

Teachers may also develop structured informal assessments, although such assessments should be grounded in research evidence. Figure 1 is an example of a structured informal assessment developed by the first author (Bruce, 2008). Adaptations for children who are blind are included. The commercial tools presented above are intended for use with younger children. The structured informal assessment (Figure 1) may also be used with older students with multiple disabilities who might benefit from direct instruction of object permanence in the context of age appropriate tasks.

$<$ See Table 1 $>$

$<$ See Figure 1 $>$

\section{Teaching Object Permanence}

Direct instruction can accelerate the development of object permanence in children with disabilities (Kahn, 1976, 1984; Morss, 1984: Rogers \& Puchalski, 1988) and is more effective than general stimulation programs in supporting mastery of object permanence (Sloper, Glenn, \& Cunningham, 1986). The closely related precursor skills of visual tracking, visually directed reach, and grasp should be developed before working directly on object permanence tasks with children who have functional vision and sufficient motor skills.

Spence and Capt (1994) found that it was critical to first gain the visual attention (of sighted children) before introducing the task. Pasnak and Pasnak (1987) found that attention and interest can be maintained best by varying the objects to be concealed and the covers used. Interfering behaviors are common in children with developmental delays, 
so repeating the task when distraction occurs and providing prompts until children are successful are additional strategies (Ilmer, Rynders, Sinclair, \& Helfrich, 1981). Pasnak and Pasnak (1987) also found that it was important to name the object before concealment and again when asking children to locate the object. Several researchers have reported the importance of concealing highly desirable objects so that locating the objects becomes a powerful form of direct reinforcement (Bell \& Richmond, 1984; Karlan, 1983; Pasnak \& Pasnak, 1987; Spence \& Capt, 1994). These researchers assert that it is more reinforcing and instructionally effective to allow children to interact with the located desirable objects as opposed to providing indirect reinforcement.

Individualized, structured play spaces can be used to support the development of object constancy knowledge and early object permanence knowledge in young children who are blind or with multiple disabilities. Anthony, Bleier, Fazzi, Kish, and Progund (2002) refer to such spaces as "reactive spatial environments" (p. 346) where objects have consistent locations, pointing out that the predictability of such spaces supports children to build memory. Lillie Nielsen's "Little Room” is a structured enclosed play space that features the suspension of objects attached to the ceiling of the space with elastic (Nielsen, 1991). A resonance board may be placed underneath the Little Room to allow children to receive vibratory and auditory information as they move about. The Little Room provides children with opportunities to associate specific objects with specific locations within the Little Room. Early awareness of objects is initially gained as children accidentally touch or move the suspended objects. This builds to intentional actions on objects (such as grasping and releasing objects), repetition of motor acts on 
objects, integration of sensory information gained by interacting with objects, and increased knowledge of object properties and object permanence (Nielsen, 1992)

Adults may support the development of object permanence in children who are blind by being observant of how children respond to auditory information (Shier, 1985). For example, children might become very quiet and still in response to certain sounds. At times, this may indicate a particular interest in a sound or knowledge of the object that produces it. Such reactions might suggest opportunities that adults can provide for children to learn about the objects or people that produce these interesting sounds, thus building toward object permanence and person permanence. These reactions may also be expressions of early object permanence knowledge.

Children who are blind and have not yet demonstrated any object permanence knowledge need opportunities to explore the object while it is named and to coactively participate in the concealment process (Rogers \& Puchalski, 1988). This can be achieved with the adult's hands partially under-lapping the child's hands. In this way the child can be in control of the exploration, receive some guidance to explore the whole object, and adult and child can move together to cover and uncover the object. Objects will first be located immediately after concealment in one location. Later, objects will be located at the last location of interaction with the object. Supporting children to immediately search for dropped objects can also support the development of object permanence. Games that involve hiding objects may be both enjoyable and helpful to the achievement of object permanence (Keller \& Carry, 1992). Touch cues may be provided to encourage the child to reach for these familiar objects (Anthony, Bleier, Fazzi, Kish, \& Pogrund, 2002). 
Children who are visually impaired or blind can be supported to gain object permanence knowledge by having organized environments. Their preferred toys and objects used in their daily care should be kept in consistent locations (Anthony, Bleier, Fazzi \& Pogrund, 2002). Within the context of daily routines, they should have ample opportunities to explore the objects and to associate locations, containers, and the objects stored in each (Monaco, 2002). For example, children might benefit by having a low cupboard that they are allowed to explore. This will encourage the development of object permanence, which in turn will motivate mobility to the cupboard.

\section{Conclusion}

Children who are blind follow the same developmental sequence in the mastery of object permanence as children with sight. However, children who are blind rely on memory, while children with sight (including those with low vision) rely on visual perception to achieve simplistic object permanence task and mental representation to achieve more advanced object permanence tasks. Achievements in orientation and mobility and object permanence are related, with object permanence knowledge serving as a motivator for mobility. Research points to the benefits of direct instruction based on careful assessment. Research-based instructional practices to support the acquisition of object permanence knowledge include: gaining attention prior to concealment, naming the object to be concealed, concealment of varied and highly motivating objects, use of varied barriers, and direct reinforcement procedures. Literature from the field of visual impairment suggests that consistent locations for objects, games involving hiding of objects, and opportunities to search immediately for dropped objects may also support the mastery of object permanence in children with vision loss. There is a need for some 
assessment tools to provide tactile adaptations and also a need for further research on how to teach object permanence skills to children with multiple disabilities in the context of age appropriate activities and in connection to the general education frameworks. 


\section{References}

Acredolo, L. P. (1990). Behavioral approaches to spatial orientation in infancy. In A. Diamond (Ed.), The development and neural bases of higher cognitive functions (pp. 596-607). New York: Annals of the New York Academy of Sciences.

Adelson, E. \& Fraiberg, S. (1974). Gross motor development in infants blind from birth. Child Development, 45(1), 114-126.

Anderson, S., Boigon, S., \& Davis, K., \& deWaard, C. (2007). Oregon Project for Visually Impaired and Blind Preschool Children. Sixth Edition. Medford, OR: Jackson Education Service District.

Anthony, T. L., Bleier, H., Fazzi, D. L., Kish, D., \& Pogrund, R. L. (2002). Developing early skills for orientation and mobility. In R. Progund and D. Fazzi (Eds.), Early Focus: Working with young children who are blind or visually impaired and their families. $2^{\text {nd }}$ edition. (pp. 326-355). New York: AFB Press.

Anthony, T. L., Lowry, S. S., Brown, C. J., and Hatton, D. D. (2004). Foundations of developmentally appropriate mobility. In. T. L. Anthony, S. S. Lowry, C. J. Brown, and D. D. Hatton (Eds.). Developmentally appropriate orientation and mobility (pp. 3-121). FPG Child Development Institute. Chapel Hill, NC: University of North Carolina.

Bell, J. \& Richmond, G. (1984). Improving profoundly mentally retarded adult's performance on position discrimination. American Journal of Mental Deficiency, 89(2), 180-186.

Bigelow, A. (1990). Relationship between the development of language and thought in 
blind children. Journal of Visual Impairment and Blindness, 84(8), 14-19.

Bozeman, L. \& McCulley, R. M. (2010). Improving orientation for students with vision loss. In W. R. Wiener, P. L. Welsch, \& B. B. Blasch (Eds). Foundations of Orientation and Mobility. Volume II: Instructional strategies and practical applications. (pp. 27-54). New York; AFB Press.

Bruce, S. (2008). Structured Informal Assessment of Object Permanence.

Bruce, S. \& Zayyad, M. (2009). The development of object permanence in children with intellectual disability, physical disability, and autism, and blindness. International Journal of Disability, Development, and Education, 56(3), 229-246.

Chen, D., Friedman, C. T. \& Calvello, G. (1989). Assessing interactions with objects. In Parents \& visually impaired infants (PAVII). Louisville, KY: American Printing House for the Blind.

Eagle, R. S. (1985). Deprivation of early sensorimotor experience and cognition in the severely involved cerebral-palsied child. Journal of Autism and Developmental Disorders, 15(3), 269-283.

Fazzi, D. L. \& Klein, M. D. (2002). Cognitive focus. In R. Pogrund \& D. Fazzi (Eds.), Early focus: Working with young children who are blind or visually impaired and their families. $2^{\text {nd }}$ Edition. (pp. 107-153). New York: AFB Press.

Ferrell, K. A. (1998). Project PRISM: A longitudinal study of developmental patterns of children who are visually impaired (Final report). Greelye's Division of Special Education, University of Northern Colorado.

Forney, P. E. \& Heller, K. W. (2004). Sensorimotor development: implications for the 
educational team. In F. Orelove, D. Sobsey, and R. K. Silberman (Eds.), Educating children with multiple disabilities: a collaborative approach, (pp. 193248). Fourth edition. Baltimore: Paul H. Brookes Publishing Company.

Fraiberg, S. (1977). Insights from the blind: comparative studies on blind and sighted infants. New York: Basic Books, Inc., Publishers.

Gerhardt, J. B. (1982). The development of object play and classificatory skills in a blind child. Journal of Visual Impairment and Blindness, 76(6), 219-223.

Hammes, J. G. \& Langdell, T. (1981). Precursors of symbol formation and childhood autism. Journal of Autism and Developmental Disorders, 11(3), 331-346.

Harrell, L. (1983). The visually impaired preschooler with an emphasis on medical intervention. ERIC: 249698

Hatton, D. D., Anthony, T. L., Lowry, S. S. \& Brown, C. J. (2004). Module: Developmentally Appropriate Orientation and Mobility. Session 3: Cognitive Development (pp. 1-27). EIVI-FPG Child Development Institute. Chapel Hill, NC: University of North Carolina, Chapel Hill.

Hatton, D. D., Bailey, D. B., Burchinal, M. R. \& Ferrell, K. A. (1997). Developmental growth curves of preschool children with vision impairments. Child Development, 68(5), 788-806.

Horobin, K. \& Acredolo L. P. (1986). The role of attentivenesss,, mobility history, and separation of hiding sites on Stage IV search behavior. Journal of Experimental Child Psychology, 41, 114-127.

Hupp, S. C., Able, H. \& Conroy-Gunter, M. (1984). Assessment of sensori-motor abilities of severely retarded children and adolescents. Diagnostic, 9(4), 208-217. 
Ilmer, S., Rynders, J., Sinclair, S., \& Helfrich, D. (1981). Assessment of object permanence in severely handicapped students as a function of motor and prompting variables. Journal of the Association for the Severely Handicapped (JASH), 6(3), 30-40.

Johnson-Martin, N. M., Attermeir, S. M., \& Hacker, B. J. (2004). The Carolina Curriculum for Infants \& Toddlers with Special Needs. Third Edition. Baltimore: Paul H. Brookes Publishing Co.

Kahn, J. V. (1976). Acceleration of object permanence with severely and profoundly retarded children. ED 125296.

Kahn, J. V. (1984). Cognitive training and initial use of referential speech. Topics in Language Disorders, 5, 14-28.

Karlan, G. R. (1983). The effects of preference for objects and repeated measures upon the assessed level of object permanence and means/end ability in severely handicapped students. Journal of the Association for the Severely Handicapped (JASH), 5(2), 174-193.

Keller, C. \& Carry, S. (1992). Sensory stimulation. IN E. Trief (Ed.), Working with visually impaired young students: A curriculum guide for birth-3 year olds. (pp. 63-97). Springfield, IL: Charles C. Thomas Publisher.

McDonnell, P. M. (1988). Developmental response to limb deficiency and limb replacement. Canadian Journal of Psychology, 42(2), 120-143.

Monaco, C. (2002). Concept development. In L. Alsop (Ed.), Understanding deafblindness: Issues, perspectives, and strategies. Volume I. (pp. 41-56). Logan, Utah: Ski Hi Institute, Utah State University. 
Moore, M. K., Borton, R., \& Darby, B. L. (1978). Visual tracking in young infants: evidence for object identity or object permanence? Journal of Experimental Child Psychology, 25(2), 183-198.

Morgan, E. (1999). The INSITE Developmental Checklist: A comprehensive developmental checklist for multihandicapped sensory impaired infants and young children. North Logan, UT: SKI-HI Institute, Utah State University.

Morss, J. R. (1984). Enhancement of object-permanence performance in the Down's syndrome infant. Child: Care, Health and Development, 10(1), 39-47.

Nielsen, L. (1991). Spatial relations in congenitally blind infants: a study. Journal of Visual Impairment and Blindness, 85(1), 11-16.

Nielsen, L. (1992). Space and self. Copenhagen, Denmark: SIKON.

Parks, S. (2004). HELP Strands. Curriculum-Based Developmental Assessment. Birth to Three Years. Second Edition. Adapted from the Hawaii Early Learning Profile. Palo Alto, CA: Vort Corporation.

Pasnak, C. F. \& Pasnak, R. (1987). Accelerated development of object permanence in Down's syndrome infants. Child, Care, Health and Development, 13(4), 247-255.

Piaget, J. (1952). The origin of intelligence in children. M. Cook (trans.). New York: International University Press.

Piaget, J. (1954). The construction of reality in the child. M. Cook (trans.). New York: Basic Books.

Robinson, C. C. \& Robinson, J. H. (1978). Sensorimotor functions and cognitive development. In M. E. Snell (Ed.), Systematic instruction of the moderately and severely handicapped, (pp. 102-156). Colombus, OH: Charles E. Merrill 
Publishing Co.

Rogers, S. J. \& Puchalski, C. B. (1988). Development of object permanence in visually impaired infants. Journal of Visual Impairment and Blindness, 82(4), 137-142.

Ross, S. \& Tobin, M. J. (1997). Object permanence, reaching, and locomotion in infants who are blind. Journal of Visual Impairment and Blindness, 91(1), 25-32.

Schwartz, M. (1984). The role of sound for space and object perception in the congenitally blind infant. Advances in Infant Research, 3, 23-56.

Shier, S. H. (1985). The roots of orientation and mobility: Birth to three. Austin, Texas: Texas School for the Blind and Visually Impaired.

Silverstein, A. B., Pearson, L. B., Keller, M. H. \& McLain, R. E. (1982). A test of the similar sequence hypothesis. American Journal of Mental Deficiency, 86(5), 551553.

Simpkins, K. E. (1979). Development of the concept of space. Journal of Visual Impairment and Blindness, 73(3), 81-85.

Sloper, P., Glenn, S. M. \& Cunningham, C. C. (1986). The intensity of training on sensori-motor development in infants with Down's syndrome. Journal of Mental Deficiency Research, 30(2), 149-162.

Spence, M. J. \& Capt, D. B. (1994). The effect of multimodal reinforcer of object concept performance and off-task behavior of children with Down syndrome. InfantToddler Intervention: the Transdisciplinary Journal, 4(2), 75-85.

Stillman, R. (Ed.). (1978). The Callier-Azusa Scale. Dallas: Callier Center for Communication Disorders, The University of Texas at Dallas.

Warren, D. H. (1994). Blindness and children: An individual differences approach. New 
York: Cambridge University Press.

Wright, L., Lewis, V., \& Collis, G. M. (2006). Imitation and representational thought in young children with Down syndrome. British Journal of Developmental

Psychology, 24, 429-450. 
Table 1: Assessment Tool Items on Object Permanence

\begin{tabular}{|c|c|c|c|}
\hline Assessment & Section & $\operatorname{Page}(\mathrm{s})$ & $\operatorname{Item}(\mathrm{s})$ \\
\hline \multirow[t]{3}{*}{ Oregon } & Cognitive & 4 & 36,37 \\
\hline & Vision Skills & $37-39$ & $10,12,15,18,19,20,37,38$ \\
\hline & Compensatory Skills & $25-26$ & $8,9,17,18,26$ \\
\hline INSITE & Object Permanence & $50-51$ & $1-25$ \\
\hline \multirow[t]{10}{*}{ Callier-Azusa } & Perceptual Abilities & 22 & 5(B) (Visual) \\
\hline & & 23 & $6(D)$ \\
\hline & & 24 & 10 \\
\hline & & 26 & 5(B) (Tactile) \\
\hline & Cognitive & 40 & $2(C)$ \\
\hline & Development & 42 & $6(\mathrm{~A}), 6(\mathrm{~B})$ \\
\hline & & 44 & $7(\mathrm{~A})$ \\
\hline & & 46 & $8(\mathrm{~A})$ \\
\hline & & 48 & $9(C)$ \\
\hline & & 50 & $11(\mathrm{~A})$ \\
\hline \multirow[t]{5}{*}{ HELP } & Cognition: Object & 5 & $1.09,1.20,1.32,1.49,1.62$ \\
\hline & Permanence & & $1.78,1.80,1.81,1.94,1.113$ \\
\hline & Spatial Relations & 6 & $1.76,1.88$ \\
\hline & Learning Rules and & 22 & 1.115 \\
\hline & Expectations & & \\
\hline Carolina & Cognition & $171-188$ & $\begin{array}{l}5 h, 5 i, 5 l, 5 m, 5 n, 5 o, 5 p, 5 q \\
5 s, 5 t, 5 u, 5 x, 5 y, 5 b b\end{array}$ \\
\hline
\end{tabular}




\section{Figure 1: Structured Informal Assessment of Object Permanence}

1. Does the child visually follow objects in any direction and across midline? (This is a visual behavior believed to be a precursor to object permanence in children with sight.)

*The child who is blind may follow the object tactilely.

2. Does the child visually follow people in any direction? (This is also a visual behavior believed to be a precursor to object permanence in children with sight.)

*The child who is blind may turn his/her head in the direction of the continuous voice of a person in movement. The child may also turn to the place where the sound stopped when the individual stops moving and talking.

3. Does the child react when an object or person is hidden from view (while he/she is watching)?

*The child who is blind may also have an emotional reaction when an object disappears from touch.

4. Can the child locate an object that you have partially concealed while he/she is watching?

*The child who is blind may demonstrate this early object permanence knowledge when part of an object (that was partially and coactively concealed) is touched by some part of his/her body.

5. Can the child locate an object that you have fully concealed while he/she is watching?

*The child who is blind may demonstrate this knowledge when some part of the object (that was fully and coactively concealed) is touched by some part of his/her body. 
6. Can the child locate an object that you have partially concealed when there is a time delay in playing with the object? How long of a delay?

*The child who is blind may demonstrate this knowledge when part of the object (that was partially concealed by another) is touched by some part of his/her body. Note that early performance of this behavior is dependent on the child tactilely exploring the object in a specific location and then locating the same object in the same location following time-delay.

7. Can the child locate an object that you have fully concealed when there is a time delay in playing with the object? How long of a delay?

* The child who is blind may demonstrate this knowledge when part of the object (that was fully concealed by another) is touched by some part of his/her body. This will first emerge in children who are blind at the last place in which they tactilely explored the object.

8. Does the child search for an object in its usual place?

*The child who is blind will use orientation skills within the room and subenvironments within the room to locate the object. It is important to keep the objects in stable places and to teach the child their locations.

9. Does the child search for an object when it is NOT in its usual place?

*This would not be an appropriate skill to teach unless the child has already tactilely explored the object and associates a specific sound with the object. The child who is blind may use his/her orientation and mobility skills and search behaviors to locate objects that have been moved/misplaced, especially after reaching to sound in the absence of tactile exploration has been achieved. 
Bruce, S. (2008). 